\title{
Parque Arqueológico del Megalitismo en Gorafe (Granada)
}

Juan José Manrique López, Asociación para el Desarrollo Rural Comarca de Guadix (Granada)

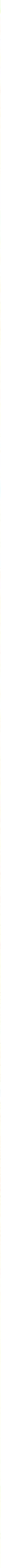

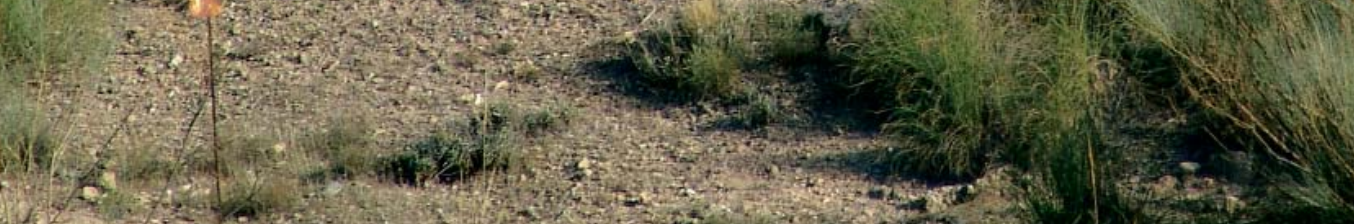

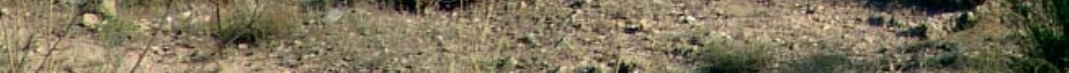


El proyecto sobre el megalitismo en Gorafe surge a finales de los noventa con objeto de poner en valor los numerosos dólmenes localizados en los márgenes del barranco del río Gor. Tomando como punto de partida la interacción entre patrimonio cultural y natural, se puso en marcha esta iniciativa en la que aunaron esfuerzos el Ayuntamiento de Gorafe, LÍDER Comarca de Guadix S.L., la Diputación Provincial de Granada y la Delegación Provincial de Cultura de la Junta de Andalucía en Granada. La filosofía del proyecto era potenciar el patrimonio cultural como factor de desarrollo económico y social, a la vez que se reforzaba la identidad cultural de la zona, una de las más deprimidas de la provincia.

El pueblo de Gorafe está situado en la parte norte de la provincia de Granada, en las altiplanicies granadinas, a 92 km de la capital, en la margen derecha del río Gor, el cual ha ido labrando en los dos últimos millones de años un barranco de abruptas pendientes, con una diferencia de cotas entre los bordes del valle y el arroyo de unos 150 metros. El resultado es un relieve de gran atractivo paisajístico y ambiental. Precisamente es, en los bordes de este cañón, donde se localizan una ingente cantidad de sepulcros megalíticos; uno de los conjuntos de mayor importancia, no sólo de la provincia de Granada, sino también de Andalucía, tanto por el número de estructuras como por la variedad y calidad de las mismas. Esta es razón suficiente para que despertarán la atención de los investigadores ya desde la segunda mitad del S. XIX, primero por Manuel de Góngora (Antigüedades Prehistóricas en Andalucía, 1868), los hermanos Louis y Henri Siret y el matrimonio alemán Georg y Vera Leisner (Die Megalithgräber der Iberischen Halbinsel. Der Süden, 1943). A finales de los años 50, los investigadores García Sánchez y Spanhi elaboraron el catálogo más completo hasta la fecha, calculando en 238 los dólmenes existentes en el valle, aunque casi un centenar de ellos hayan ya desaparecido, debido a la falta de protección y de recursos para su conservación, no sólo por razones naturales sino también antrópicas (saqueadores clandestinos, puestos de caza, labores agrícolas etc.).

El Proyecto de Parque Megalítico se fundamenta en la necesidad de potenciar las actitudes de respeto y sensibilidad hacia nuestro rico patrimonio, el uso racional y disfrute del mismo, cimentándolo sobre la base del conocimiento científico y sobre la comunicación.

La primera fase de actuación (2000-2004) implicó la investigación y adecuación de los megalitos, lo que permitió la interpretación y difusión de la cultura megalítica en su contexto pasado y presente con la aplicación de diferentes metodologías de carácter didáctico y pedagógico. Para la comprensión del Parque se crearon tres itinerarios o rutas (una cuarta en proyecto) de acceso diversificadas, marcando senderos de paso a las distintas zonas culturales y ambientales, dotándolas de elementos expositivos, tales como paneles informativos generales que analizan la evolución poblacional y distribución espacial de los monumentos funerarios. Esta información sobre el terreno se completó con la edición de diferente material promocional y didáctico en diferentes soportes (videos, guías, monografías o multimedia). En esta primera fase también se comenzaron las obras del Centro de Interpretación del Megalitismo, un espectacular edificio subterráneo de algo más de 600 $\mathrm{m}^{2}$, que recuerda la forma de un dolmen y que sirve de recepción a los visitantes y paso previo a la visita del conjunto. Así mismo, en el conjunto de medidas de promoción del parque y del territorio se desarrolló un proyecto de cooperación transnacional con el Operatore Colletivo Leader I/ de Sa Corona Arrùbia (Cerdeña, Italia).

Tras sentar los pilares básicos de una articulación estratégica y desarrollo de los valores patrimoniales como fundamento de una política rural de reactivación económica y social de la zona oriental de la Comarca de Guadix, se abre una segunda fase de actuación o un segundo nivel de inter- 


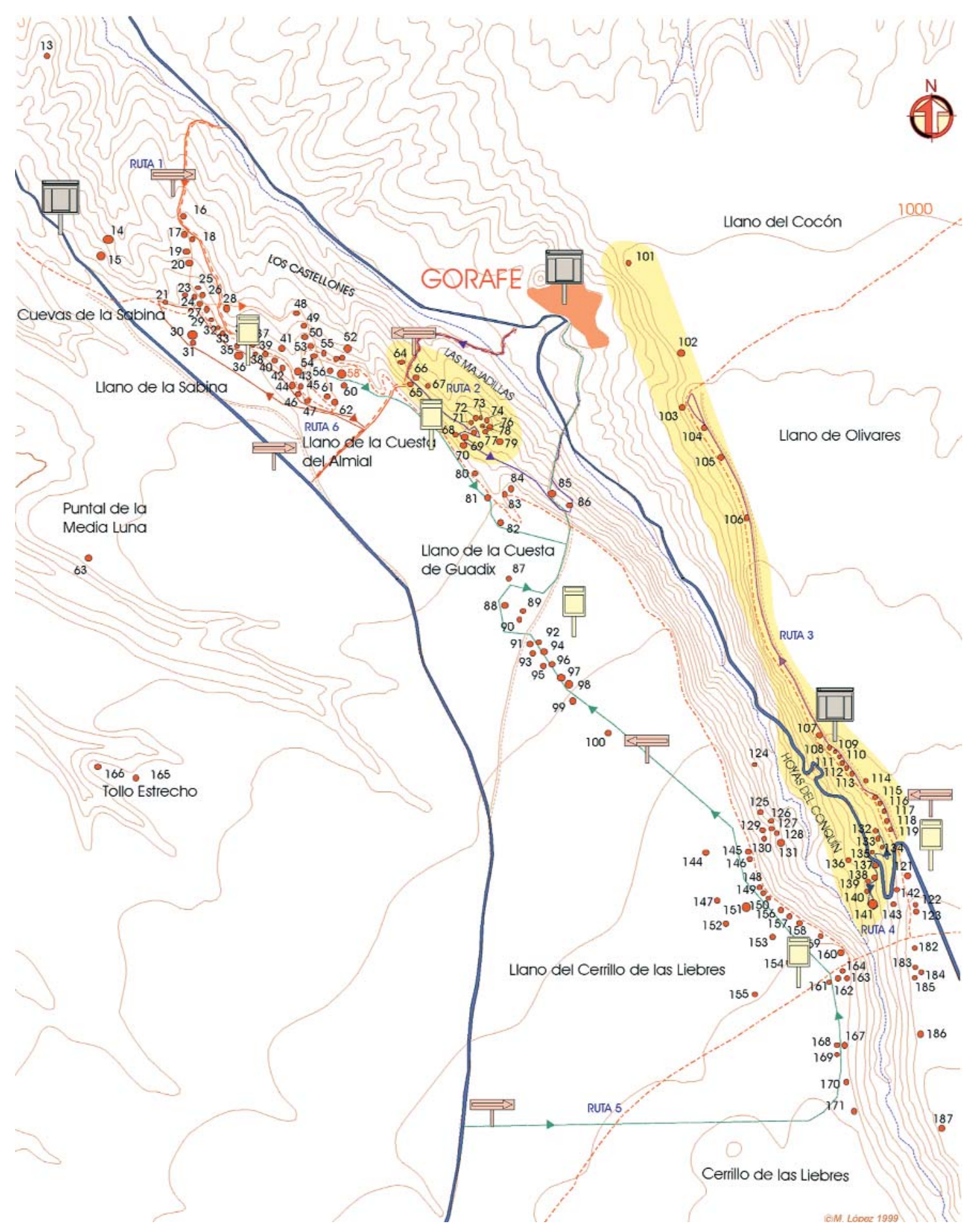


3. Cartelería de bienvenida a la entrada del Parque Megalítico / Foto: ANTONIO LóPEZ

5. Ruta 4, Hoyas del Conquín. Dolmen 134 / Foto: ANTONIo LóPEZ
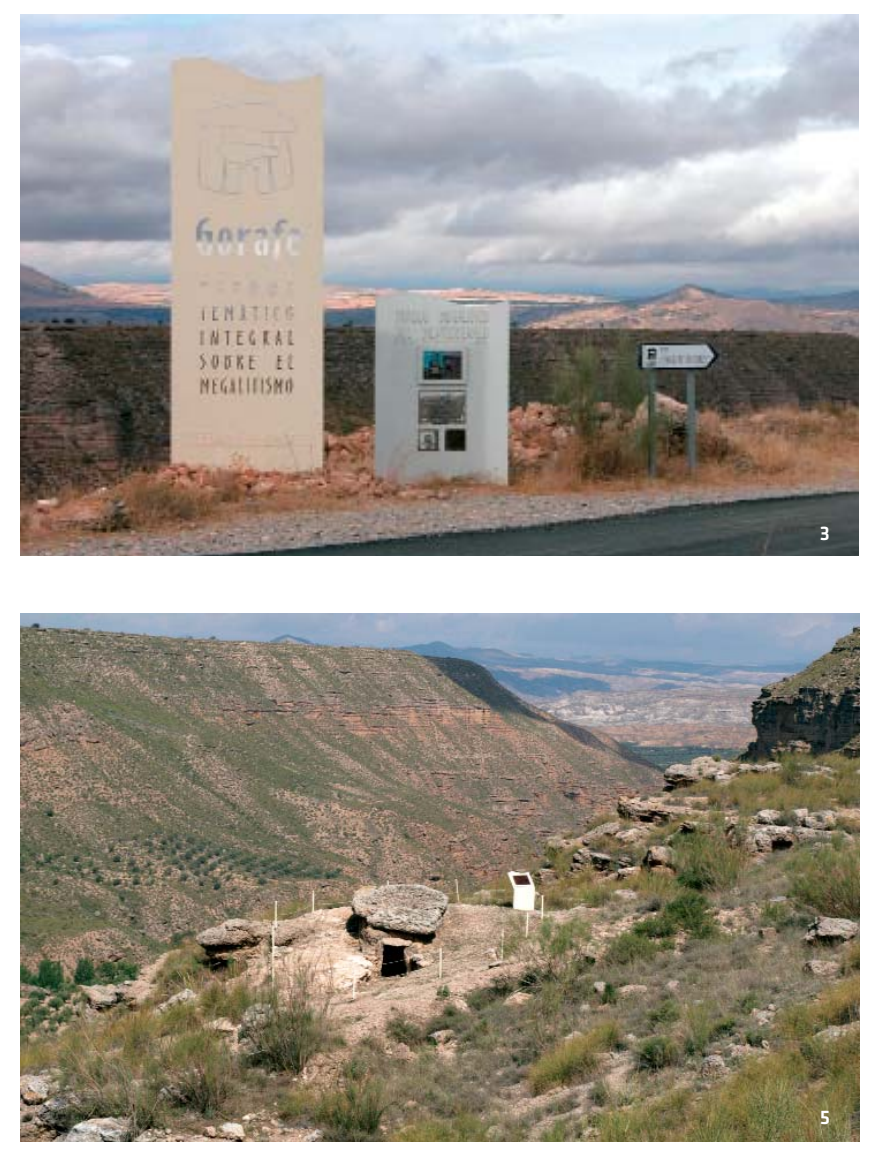

acción que se desarrollará entre el 2004-2008 con una serie de proyectos encaminados no sólo a consolidar las actuaciones precedentes, sino a lanzar nuevas líneas de cooperación. El edificio proyectado como centro de interpretación se termina con la urbanización del entorno y con la adecuación museográfica del mismo. Para esto último se convoca un concurso museográfico a finales de 2005 al que concurren varias empresas especializadas en museografía. Una segunda vía de intervención se encamina a la «redidactización» de los itinerarios de visita, con la homogenización de los contenidos de los paneles, una nueva edición bajo la imagen corporativa del centro, así como la instalación de recursos pedagógicos que posibiliten una interrelación más directa del visitante con los elementos patrimoniales mostrados. Así mismo, la adaptación de lugares de descanso y estacionamiento de vehículos en la cabecera de cada una de las rutas completan la dotación de este parque arqueológico. La edición de una guía de bolsillo, dentro de una serie de guías patrimoniales de la Comarca promovidas por el Centro de Iniciativas Turísticas de la Comarca de Guadix, permite un acercamiento libre y ameno al entorno cultural y natural del valle del río Gor. Pero no sólo se interviene a nivel local, porque si bien en la fase anterior se persiguió establecer re-
4. Ruta 2, Majadillas. Dolmen 69 / Foto: ANTONIo López

6. Panorámica aérea del río Gor/ Foto: IKARUM.coM
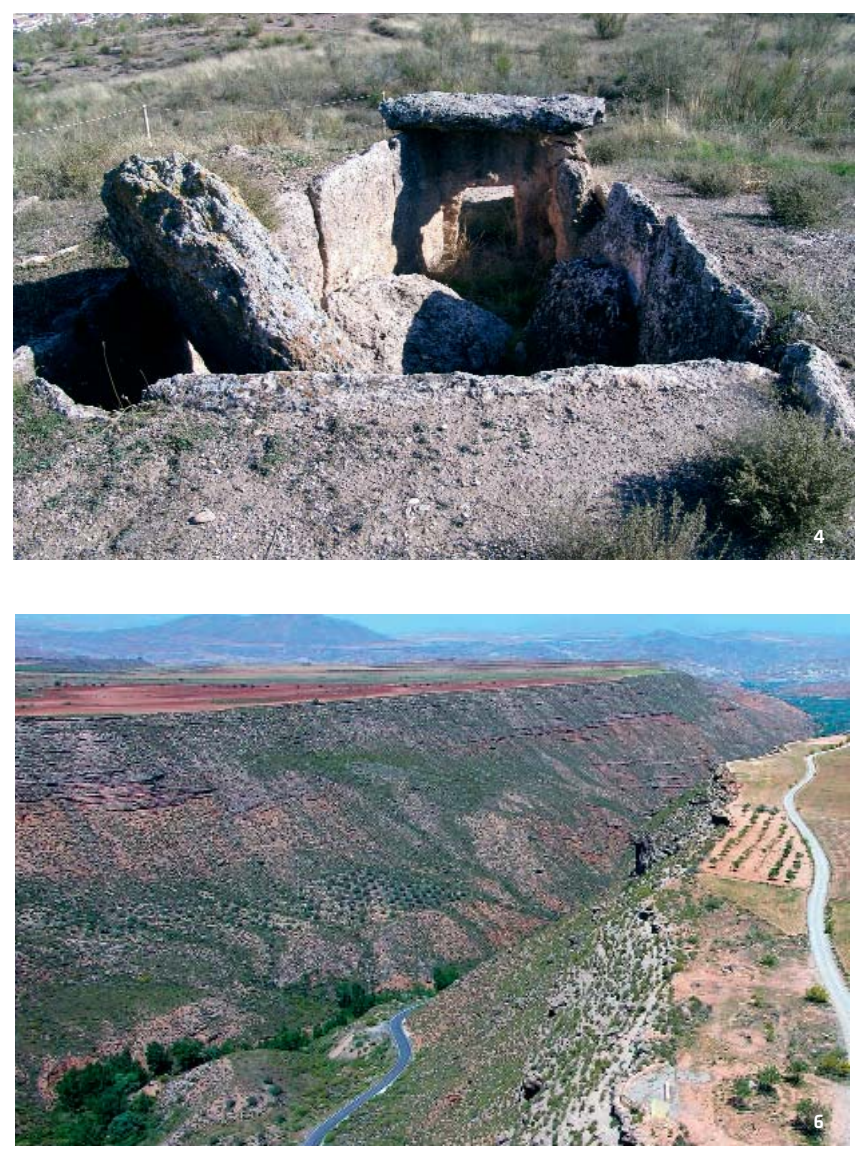

laciones de cooperación a nivel transnacional, ahora se promueve una acción conjunta de cooperación, financiada en el marco del Programa Regional Leader Plus de Andalucía, en la que se integran seis comarcas de nuestra Comunidad Autónoma en las que los espacios dolménicos se conciben como referente patrimonial de desarrollo y sensibilización social. Las acciones abordadas incluyen la edición de productos multimedia, el documental El Megalitismo Andaluz, la catalogación e reinventariado de los dólmenes existentes, así como diversas actuaciones encaminadas a la promoción de los valores culturales, paisajísticos y sociales de los espacios dolménicos.

Con todo esto, el megalitismo de la zona de Gorafe se convierte así en un referente local y regional de desarrollo sostenible de una Comarca que rastrea en su patrimonio en busca de señas de identidad y reafirmación social en la que cimentar futuras actuaciones de desarrollo económico y social. Protección y conservación, sensibilización, valorización, difusión pasan de ser meros conceptos a constituir los fundamentos en los que tanto el Ayuntamiento de Gorafe como la globalidad de ayuntamientos de la Comarca apoyan su política de futuro. 